\title{
0mentin-1 levels in patients with premature coronary artery disease, metabolic syndrome and healthy controls. Short communication
}

\author{
David Stejskal ${ }^{\mathrm{a}, \mathrm{b}, \mathrm{c}}$, Jan Vaclavik ${ }^{\mathrm{d}}$, Ales Smekal ${ }^{\mathrm{d}}$, Gabriela Svobodova ${ }^{\mathrm{a}, \mathrm{b}}$, Radmila Richterova ${ }^{\mathrm{e}}$, Marek Svestak ${ }^{\mathrm{a}, \mathrm{b}}$
}

\begin{abstract}
Objectives. Omentin-1 is an adipokine which could have a protective role against the manifestation of atherosclerosis. Only limited data are available on omentin-1 serum values in patients with premature clinical manifestations of atherosclerosis.

Design and Methods. We tested omentin-1 in human serum by ELISA method in 61 individuals with a premature manifestation of coronary artery disease (CAD), 40 patients with metabolic syndrome and 40 healthy control subjects. Results. Omentin-1 serum levels were significantly lower in patients with CAD (103.1 $\pm 62.7 \mathrm{mg} / \mathrm{L})$ compared to metabolic syndrome $(668.2 \pm 339.6 \mathrm{mg} / \mathrm{L})$ and healthy subjects $(623.0 \pm 373.5 \mathrm{mg} / \mathrm{L})(P<0.01)$. In CAD patients, omentin-1 serum levels did not differ between patients sampled in the acute phase of myocardial infarction $(n=28 ; 110.3 \pm 82.4$ $\mathrm{mg} / \mathrm{L})$ and in the chronic phase several months or years after myocardial infarction $(\mathrm{n}=33 ; 97.0 \pm 39.3 \mathrm{mg} / \mathrm{L})(P=0.41)$. We found a weak positive correlation between omentin- 1 and body mass index $(r=0.21, P=0.014)$. No significant correlation was found between peak cardiac troponin T and omentin-1 (correlation coefficient $r=0.118, P=0.406$ ).

Conclusion. Serum omentin-1 seems to be a useful biomarker of coronary artery disease across the whole age spectrum.
\end{abstract}

Key words: omentin-1, acute myocardial infarction, coronary artery disease, premature manifestation, adipokines, ELISA

Received: November 12, 2015; Accepted with revision: March 30, 2016; Available online: April 20, 2016 http://dx.doi.org/10.5507/bp.2016.019

${ }^{a}$ AGEL Research and Training Institute, Prostejov, Czech Republic

'Institute of Medical Chemistry and Biochemistry, Faculty of Medicine and Dentistry, Palacky University Olomouc, Czech Republic 'Department of Biomedical Sciences, Faculty of Medicine, Ostrava University, Czech Republic

${ }^{d}$ Department of Internal Medicine I - Cardiology, University Hospital Olomouc and Faculty of Medicine and Dentistry, Palacky University Olomouc, Czech Republic

${ }^{e}$ Agel Laboratories, Novy Jicin, Czech Republic

Corresponding author: Jan Vaclavik, e-mail:vaclavik.j@centrum.cz

\section{INTRODUCTION}

Omentin-1 (intelectin-1, intestinal lactoferin receptor, endothelial lectin HL-1, galactofuranose-binding lectin) is a newly identified secretory protein that is highly and selectively expressed in the visceral relative to the subcutaneous adipose tissue (adipokine). The mature omentin-1 is a secretory glycoprotein consisting of 295 aminoacids and 1-linked oligosacharides, and its basic structural unit is a $120-\mathrm{kDa}$ homotrimer in which $40-\mathrm{kDa}$ polypeptides are bridged by disulfide bonds. Omentin has been identified in other tissues at lower expression levels such as Paneth cells, endothelial cells, and visceral adipose stromal-vascular cells ${ }^{1}$.

A homologue of omentin has been identified which shares $83 \%$ amino acid identity with omentin- 1 and is referred to as omentin-2. Two omentin genes, omentin 1 and omentin 2, are localized adjacent to each other in a chromosomal region which has been linked to type 2 diabetes in several populations ${ }^{2}$. Omentin- 1 has been shown to be the major circulating isoform in human plasma.

A recent study has found that patients on hemodialysis had a low serum concentration of omentin-1 (ref. ${ }^{3}$ ). Another recent study has suggested a strong association between decreased omentin-1 levels in serum and peripheral artery disease (PAD) and its severity ${ }^{4}$. Decreased serum omentin-1 levels in could be considered as an independent predictive marker of the presence and disease activity of inflammatory bowel disease ${ }^{5}$. Omentin- 1 is also an adipokine with anti-inflammatory effects that has been associated with different metabolic disorders ${ }^{6}$.

Recent studies have shown that omentin-1 values were decreased in older men and women with coronary artery disease ${ }^{7,8}$. However, the role of omentin-1 in the pathophysiology of coronary artery disease and its early manifestation in younger people is not well defined.

\section{MATERIALS AND METHODS}

The study was approved by the Ethics Committee of University Hospital Olomouc, Czech Republic. A total of 40 non-obese healthy individuals, 40 individuals with metabolic syndrome and 61 individuals with premature coronary artery disease (CAD; males aged 18-45 and females 18-55 years) were recruited for the study. Metabolic syndrome was defined according to the standard harmonized definition ${ }^{9}$. All patients with CAD had a history of 
acute myocardial infarction, defined by the Third universal definition ${ }^{10}$.

Fasting blood samples were taken from the cubital vein after a several-minutes rest in a half-sitting position. In CAD patients, blood was sampled either during index hospitalization for acute myocardial infarction or in the chronic phase several months or years after myocardial infarction.

Serum samples were separated in a cooled centrifuge $\left(4{ }^{\circ} \mathrm{C}\right)$ at $3000 \mathrm{~g}$ for $20 \mathrm{~min}$ and stored at $-80{ }^{\circ} \mathrm{C}$. Time between sampling and centrifugation was standardized between 15-30 min. Omentin-1 serum levels in human serum were determined quantitatively by a sandwich ELISA assay (Max002 Dynatech, Biovendor, Brno, Czech Republic). Standards, quality controls and samples were incubated at $37{ }^{\circ} \mathrm{C}$ in microplate wells pre-coated with polyclonal anti-human omentin-1 antibody. After $120 \mathrm{~min}$ incubation and washing, biotin labelled polyclonal antihuman omentin-1 antibody was added and incubated at $37^{\circ} \mathrm{C}$ with captured omentin-1 for $30 \mathrm{~min}$. After another washing, streptavidin-HRP conjugate was added. After 30 min incubation at $37^{\circ} \mathrm{C}$ and the last washing step, the remaining conjugate was allowed to react with the substrate solution (TMB). The reaction was stopped by the addition of an acidic solution and the absorbance of the resulting yellow product was measured. The absorbance was proportional to the concentration of omentin-1.

To validate the reliability of the assay, we tested the limit of detection and the precision of the assay. The limit of detection of the assay was $0.5 \mathrm{mg} / \mathrm{L}$ and the limit of quantification (analytical the limit of the detection multiplied by sample dilution) was $1.1 \mathrm{mg} / \mathrm{L}$; the intra-assay coefficient of variation $(\mathrm{CV})$ was less than $6 \%$ and inter-assay coefficient of variation (CV) were always less than $12 \%$.

The data obtained were processed by the Medcalc software (Medcalc, Mariakerke, Belgium). The value of $P<$ 0.05 was considered as statistically significant. Because of anomalous data distributions of evaluated parameters, Spearman's correlation coefficients were used to establish the association between omentin-1 levels and the other parameters. Comparison of omentin-1 serum values between subjects with and without AIM were performed by either the Student's t test or Mann-Whitney test according to the data distribution. All data are presented as medians and/ or means \pm standard deviation. ROC curves with AUC were prepared.

\section{RESULTS}

The study analysed 141 subjects - 61 patients with premature CAD, 40 patients with metabolic syndrome and 40 healthy controls. Mean age in the premature CAD,

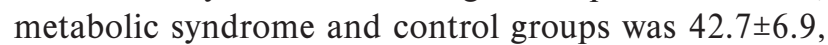
$61.5 \pm 10.7$ and $35.5 \pm 9.4$ years respectively. There was a predominance of males $(72.7 \%, 87.5 \%$ and $82.5 \%)$ in all groups. 48 (78.7\%) patients in the CAD group had a history of acute ST elevation myocardial infarction (STEMI). The remaining 13 had a history of non-ST elevation myocardial infarction (NSTEMI). No patient had a history of heart failure.
Omentin-1 serum levels were found to be significantly lower in patients with premature CAD $(103.1 \pm 62.7 \mathrm{mg} / \mathrm{L})$ compared to metabolic syndrome $(668.2 \pm 339.6 \mathrm{mg} / \mathrm{L})$ and healthy subjects $(623.0 \pm 373.5 \mathrm{mg} / \mathrm{L})(P<0.01)$ (Fig. 1). In CAD patients, omentin-1 serum levels did not differ between patients sampled in the acute phase during the first 5 days after acute myocardial infarction ( 28 patients; $110.3 \pm 82.4 \mathrm{mg} / \mathrm{L}$ ) and in the chronic phase several months or years after myocardial infarction (33 patients; $97.0 \pm 39.3 \mathrm{mg} / \mathrm{L})(P=0.41)$.

Omentin-1 value was not found to be dependent on the extent of myocardial infarction as assessed by the peak of cardiac troponin $\mathrm{T}$ (cTnT) in the acute phase: the mean troponin cTnT in the acute phase of myocardial infarction in CAD patients was $3150.9 \pm 3361.4 \mathrm{ng} / \mathrm{L}$ (normal upper reference limit is $14 \mathrm{ng} / \mathrm{L}$ ). No significant correlation was found between peak cTnT and Omentin-1 (correlation coefficient $\mathrm{r}=0.118, P=0.406)$.

Mean body mass index (BMI) was significantly higher in patients with metabolic syndrome $\left(35.0 \pm 3.2 \mathrm{~kg} / \mathrm{m}^{2}\right)$ compared to CAD patients $\left(28.7 \pm 5.0 \mathrm{~kg} / \mathrm{m}^{2}\right)$ and healthy controls $\left(27.5 \pm 1.7 \mathrm{~kg} / \mathrm{m}^{2}\right)(P<0.001)$. We found a weak positive correlation between omentin-1 and body mass index (BMI; $\mathrm{r}=0.21, P=0.014)$.

\section{DISCUSSION}

The study showed that patients with premature CAD had significantly lower serum omentin-1 levels than patients with metabolic syndrome and healthy controls.

To our knowledge, this is the first study to assess omentin-1 levels in "young" patients with premature manifestations of atherosclerosis. Our results are in concordance with previous studies in older patients. In postmenopausal women who had undergone coronary angiography, patients with angiographic CAD had significantly decreased

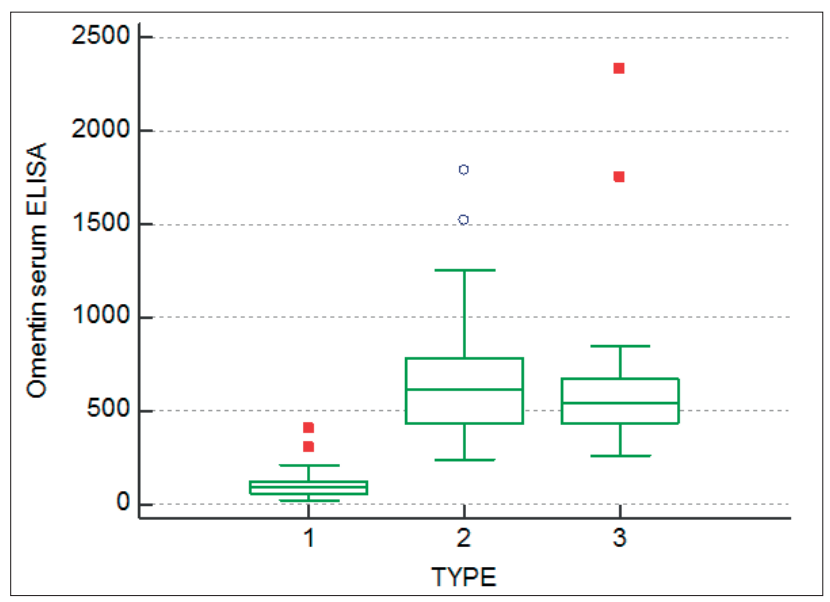

Fig. 1. The box plots showing distribution of omentin-1 values (in $\mathrm{mg} / \mathrm{L}$ ) in patients with premature coronary artery disease (1), metabolic syndrome (2) and healthy controls (3). Middle lines in the boxes represent the medians, lower and upper box hinges represent the $25^{\text {th }}$ and $75^{\text {th }}$ percentile, upper and lower line ends represent the 1.5 interquartile range, separate points represent the outliers. 
omentin-1 levels, compared to those without CAD ( ref. $\left.^{7}\right)$. Similarly, older males, mean age 63 years with CAD had markedly lower plasma levels of omentin-1 than control subjects $^{8}$. In patients with metabolic syndrome, omentin-1 levels inversely correlated with the presence and angiographic severity of CAD ( ref. $^{11}$ ).

Another interesting new observation in our study is that omentin-1 levels in CAD patients did not differ between patients with acute myocardial infarction and patients in the chronic phase of CAD. In another recent study (KOZANI), at baseline, the acute myocardial infarction group also had significantly lower omentin-1 values, as well as ejection fraction, high-density lipoprotein serum levels, and higher concentrations of white blood cells (WBC), hsCRP, IL-18 and chemerin compared with healthy controls $(P<0.05)$ (ref. $\left.{ }^{12}\right)$. After 6 months of follow-up, the concentrations of omentin-1 levels in the KOZANI study considerably increased within the AMI group 9 .

In middle aged white healthy adults, the reliability of single time point measurements of omentin- 1 was found to be excellent and similar to results from the same patients 4 months later ${ }^{13}$. It is likely that only one analysis of omentin- 1 in serum is sufficient and the test does not have to be repeated ${ }^{13}$.

In one study, omentin-1 levels in blood inversely correlated with BMI, waist circumference, leptin levels, and insulin resistance as measured by the homeostasis model assessment and positively correlated with adiponectin and HDL levels ${ }^{14}$. In contrast, we found a weak but positive correlation between omentin-1 and BMI. Further studies in larger populations are needed to more precisely assess the relation of omentin-1 to BMI.

Recent data have shown a rather strong relationship between physical exercise and circulating omentin-1 levels as well as an increase in adipokine in response to 6-weeks endurance training in obese women ${ }^{15}$. These findings hint at a skeletal muscle-adipose tissue crosstalk in regard to omentin-1 regulation.

\section{CONCLUSION}

In conclusion, patients with premature CAD had significantly lower omentin-1 serum levels than patients with metabolic syndrome and healthy subjects. Thus, omentin- 1 is a potential biomarker of CAD across the whole age spectrum of patients. Further studies are needed to determine whether its assessment identifies people "at risk" of cardiovascular events in apparently healthy individuals. Possible future therapies leading to increase in omentin- 1 might have a protective effect against the CAD and other atherosclerotic vascular diseases.

Acknowledgement: This work was support by internal grant AGEL No 2012002.

Author contributions: DS: data analysis, study design, patient enrollment, statistics, manuscript writing; JV: study design, patients enrollment, manuscript writing; RR: laboratory analysis, manuscript revision and approval; MS: verification of laboratory analysis, manuscript revision and approval; GS: statistics, data analysis, manuscript revision and approval; AS: studydesign, patient enrollment, manuscript revision and approval

Conflicts of interest statement: None declared.

\section{REFERENCES}

1. Schäffler $A$, Neumeier $M$, Herfarth $H$, Fürst $A$, Schölmerich J, Büchler $C$ : Genomic structure of human omentin, a new adipocytokine expressed in omental adipose tissue. Biochemica et Biophysica acta 2005;1732:96-102.

2. Yang RZ, Lee MJ, Hu H, Pray J, Wu HB, Hansen BC, Shuldiner AR, Fried SK, MCLenithan JC, and Gong DW: Identification of omentin as a novel depot-specific adipokine in Human adipose tissue: possible role in modulating insulin action. Am J Physiol Endocrinol Metab 2006;290:E1253-E1261.

3. Kocijancic M, Vujicic B, Racki S, Cubranic Z, Zaputovic L, Dvornik S. Serum omentin-1 levels as a possible risk factor of mortality in patients with diabetes on haemodialysis. Diabetes Res Clin Pract 2015;110(1):44-50. doi: 10.1016/j.diabres.2015.06.008

4. Onur I, Oz F, Yildiz S, Kuplay H, Yucel C, Sigirci S, Elitok A, Pilten S, Kasali K, Yasar Cizgici A, Erentug V, Dinckal HM. A decreased serum omentin-1 level may be an independent risk factor for peripheral arterial disease. Int Angiol 2014;33:455-6.

5. Yin J, Hou P, Wu Z, Nie Y. Decreased levels of serum omentin-1 in patients with inflammatory bowel disease. Med Sci Monit 2015;21:11822. doi: 10.12659/MSM.892081

6. Garcés MF, Ruíz-Linares CE, Vallejo SA, et al. Maternal serum omentin-1 profile is similar in humans and in the rat animal model. Cytokine 2015;75(1):136-41. doi: 10.1016/j.cyto.2015.06.014

7. Onur I, Oz F, Yildiz S, Oflaz H, Sigirci S, Elitok A, Pilten S, Karaayvaz EB, Cizgici AY, Kaya MG, Onur ST, Sahin I, Dinckal HM. Serum omentin 1 level is associated with coronary artery disease and its severity in postmenopausal women. Angiology 2014;65(10):896-900.

8. Shibata R, Ouchi N, Kikuchi R, Takahashi R, Takeshita K, Kataoka Y, Ohashi K, Ikeda N, Kihara S, Murohara T. Circulating omentin is associated with coronary artery disease in men. Atherosclerosis 2011;219(2):811-4.

9. Alberti KG, Eckel RH, Grundy SM, Zimmet PZ, Cleeman Jl, Donato KA, Fruchart JC, James WP, Loria CM, Smith SC Jr; International Diabetes Federation Task Force on Epidemiology and Prevention; Hational Heart, Lung, and Blood Institute; American Heart Association; World Heart Federation; International Atherosclerosis Society; International Association for the Study of Obesity. Circulation 2009;120(16):1640-5.

10. Thygesen K, Alpert JS, Jaffe AS, Simoons ML, Chaitman BR, White $\mathrm{HD}$ et al. and ESC Committee for Practice Guidelines. Third universal definition of myocardial infarction. Eur Heart J 2012;33(20):2551-67.

11. Shang FJ, Wang JP, Liu XT, Zheng QS, Xue YS, Wang B, Zhao LY. Serum omentin-1 levels are inversely associated with the presence and severity of coronary artery disease in patients with metabolic syndrome. Biomarkers 2011;16(8):657-62.

12. Kodoglou NP, Tahmatzidis DK, Giannakoulas C, Kapelouzou A, Gkontopoulos A, Parissis J, Lampropoulos S, Kottas G. Serum levels of novel adipokines, omentin- 1 and chemerin, in patients with acute myocardial infarction: KOZANI STUDY. J Cardiovasc Med (Hagerstown) 2015;16:341-6.

13. Wittenbecher C, di Giuseppe R, Biemann R, Menzel J, Arregui M, Hoffmann J, Aleksandrova K, Boeing H, Isermann B,Schulze MB, Weikert C. Reproducibility of Retinol Binding Protein 4 and Omentin-1 Measurements over a Four Months Period: A Reliability Study in a Cohort of 207 Apparently Healthy Participants. PLoS One 2015;10:e0138480.

14. De Souza Batista CM, Yang RZ, Lee MJ, Glynn NM, Yu DZ, Pray J, Ndubuizu K, Patil S, Schwartz A, Kligman M, Fried SK, Gong DW, Shuldiner AR, Pollin TI, and McLenithan JC: Omentin plasma levels and gene expression are decreased in obesity. Diabetes 2007; 56:1655-61.

15. Wilms B, Ernst B, Gerig R, Schultes B. Plasma omentin-1 levels are related to exercise performance in obese women and increase upon aerobic endurance training. Exp Clin Endocrinol Diabetes 2015;123(3):187-92. 